\title{
Hydrogen mediated transport of Sn to Ru film surface
}

\author{
Nadir Faradzhev ${ }^{\mathrm{a}}$ \\ Physics Department, Rutgers University, 136 Frelinghuysen Road, Piscataway, New Jersey 08854 \\ Vadim Sidorkin \\ Faculty of Applied Sciences, TU Delft, Lorentzweg 1, 2628 CJ Delft, The Netherlands
}

(Received 21 October 2008; accepted 20 January 2009; published 19 February 2009)

\begin{abstract}
The authors report on the interaction of atomic hydrogen with $\mathrm{Sn}$ and thin $\mathrm{Ru}$ film at room temperature. The study is done using a combination of photoelectron and low energy ion scattering spectroscopies as well as scanning electron microscopy. The adsorption of hydrogen on a Sn surface leads to the formation of stannane $\left(\mathrm{SnH}_{4}\right)$, which dissociatively adsorbs on the surface of polycrystalline $\mathrm{Ru}$ film. In the range of effective Sn coverages studied (up to $1 \mathrm{ML}$ ), the resulting overlayer consists of randomly distributed three-dimensional islands with average size below $40 \mathrm{~nm}$ occupying up to several percent of the surface area. Nucleation of $\mathrm{Sn}$ is observed presumably at defect sites (e.g., grain boundaries). Ion scattering data are found consistent with Volmer-Weber growth mode: no initial transition wetting layer formation is detected. Oxidation of $\mathrm{Sn}$ islands on a $\mathrm{Ru}$ surface at room temperature results in the formation of $\mathrm{SnO}$. Neither metallic nor oxidation states of $\mathrm{Sn}$ higher than $\mathrm{Sn}^{2+}$ are observed by photoelectron spectroscopy. (C) 2009 American Vacuum Society. [DOI: 10.1116/1.3081968]
\end{abstract}

\section{INTRODUCTION}

Bimetallic systems are important for industrial applications oriented on catalysis. ${ }^{1-3} \mathrm{Ru}-\mathrm{Sn}$ catalyst has been recognized as a promising system for selective hydrogenation of a carbonyl group. ${ }^{4}$ The selectivity is explained in terms of a strong interaction between the $\mathrm{C}=\mathrm{O}$ group with the tin oxide. The proximity of $\mathrm{Sn}$ to the noble metal and the tin oxidation state are crucial to produce an active and selective catalyst. The distribution of the ionic tin in the catalyst is affected by the preparation procedure, e.g., sol-gel process, ${ }^{5}$ coimpregnation of two different ruthenium and tin precursors, ${ }^{6}$ or production from a single source precursor containing both metals. ${ }^{7}$

A large number of fundamental studies of bimetallic surfaces are focused on the influence of structural parameters on the chemical reactivity of the system., ${ }^{2,8}$ Depending on the surface temperature, the interaction of a promoter (e.g., Sn) with a single crystal surface of a noble metal catalyzing a reaction may lead to formation of an ordered surface alloy or a thin film with abrupt interface. It has been observed that atomically rough, high energy surfaces may be morphologically unstable during reaction conditions. ${ }^{9}$ In contrast to the closed packed faces, the high-index surfaces may undergo massive structural rearrangements (e.g., faceting) when covered by a metallic film. It is also shown that film growth mode on nanofaceted surface may be very different from a growth mode on the flat substrate. ${ }^{10}$ Surfaces with polycrystalline morphology and grain boundaries may also exhibit a growth mode different from a surface of a single crystal.

Formation of surface alloys is driven by difference in surface free energies. Surface alloying of $\mathrm{Sn}$ deposited on

\footnotetext{
a) Author to whom correspondence should be addressed; also at National Institute of Standards and Technology, Gaithersburg, MD 20899; electronic mail: nadir.faradzhev@nist.gov
}

$\operatorname{Pt}(111)$ and $\operatorname{Pd}(111)$ occurs at $300-400 K .^{11}$ The exothermic heats of formation of specific intermetallic compounds serve as a sufficient thermodynamic driving force for the formation of Sn-Pt alloy. A random alloy of increasing thickness was also detected at $300 \mathrm{~K}$ for vapor deposited $\mathrm{Sn}$ on $\mathrm{Rh}(111){ }^{12}$ The phase diagram of $\mathrm{Sn}-\mathrm{Ru}$ system is thoroughly studied. ${ }^{13,14}$ The solubility ranges of $\mathrm{Sn}$ in $\mathrm{Ru}$ and $\mathrm{Ru}$ in $\mathrm{Sn}$ are very small. ${ }^{15}$ On the basal plane of ruthenium, Sn prefers to segregate due to its much lower surface free energy. ${ }^{16}$ The intermixing and surface alloy bonding with $\mathrm{Sn}$ adatoms require a large thermal excursion to occur. ${ }^{14} \mathrm{Sn}$ deposition on $\mathrm{Ru}(0001)$ at temperatures $>600 \mathrm{~K}$ and upon annealing to $1000 \mathrm{~K}$ leads to alloy formation with surface $\mathrm{Sn}: \mathrm{Ru}$ atom ratio of 2:1. ${ }^{17}$ However, vapor deposition of $\mathrm{Sn}$ on this surface at low temperature $(330 \mathrm{~K})$ does not produce surface alloy, but rather results in a Stranski-Krastanov growth mode, i.e., formation of the first uniform monolayer followed by a three-dimensional (3D) growth. ${ }^{17}$

It is reported that high pressure oxidation of ultrathin $\mathrm{Sn}$ films on $\mathrm{Pd}(111)$ at $300 \mathrm{~K}$ results exclusively in $\mathrm{SnO}$ formation in the absence of intermediate or higher oxides. ${ }^{18}$ Surface Pd oxide has not been formed presumably because of strong preexisting $\mathrm{Sn}$ to $\mathrm{Pd}$ charge transfer and the low dimensionality of the oxidized Sn overlayer. Recent studies have suggested that $\mathrm{Zn}(\mathrm{II})$ can be reduced by chemisorbed hydrogen to form $\mathrm{Ru}-\mathrm{Zn}^{2+} / \mathrm{Ru}-\mathrm{Zn}$ distribution on the catalyst surface. ${ }^{19}$ This is confirmed by theoretical study focused on effect of $\mathrm{Zn}^{2+} / \mathrm{Zn}$ layer on dissociation of $\mathrm{H}_{2}$ on $\mathrm{Ru}(0001){ }^{20}$ They found that $\mathrm{Zn}^{2+}$ has a dramatic influence on the electron delocalization between molecular orbit on $\mathrm{H}_{2}$ and valence orbits of atop $\mathrm{Ru}$ atom increasing $\mathrm{H}_{2}$ dissociation barrier and resulting in zones of sparse chemisorbed $\mathrm{H}$ around $\mathrm{Zn}^{2+}$. It is shown that flowing of atomic $\mathrm{H}$ to oxidized thin $\mathrm{Ru}$ film can reduce $\mathrm{Ru}^{\mathrm{n}+}$ to metal. ${ }^{21}$ In a solid-gas reaction between metal and $\mathrm{H}$, ruthenium forms no stable binary 
hydride, ${ }^{22}$ but $\mathrm{Sn}$ does produce a stable covalent compound $\mathrm{SnH}_{4}$, which is a very volatile hydride (boiling point $221 \mathrm{~K}$ ) decomposing at room temperature (RT). ${ }^{23,24}$ Stannanes are widely used in electronic devices in the initial step of chemical vapor deposition processes. ${ }^{25,26}$

In addition to catalytic interest, $\mathrm{Sn}$ contamination of $\mathrm{Ru}-$ coated optics for extreme ultraviolet (EUV) lithography may become a potential problem $^{27,28}$ since the introduction of new powerful Sn-based laser-produced plasma sources. Hydrogen being considered for EUV optics cleaning ${ }^{21}$ may react with Sn to yield a volatile hydride, which, in turn, may subsequently dissociate on chemically active surfaces spreading contamination all over a lithography tool.

In this article, we focus on hydrogen promoted transport of $\mathrm{Sn}$ to the surface of thin polycrystalline Ru film. We discuss the structure of Sn layer, the influence of high pressure oxidation on the morphology, and Sn oxidation states on the $\mathrm{Ru}$ surface.

\section{EXPERIMENT}

The experiments were performed under ultrahigh vacuum conditions at RT using three techniques: x-ray photoelectron spectroscopy (XPS), low energy ion scattering (LEIS) spectroscopy, and scanning electron microscopy (SEM).

The morphology of Sn layer grown on the surface of Ru was imaged by a field-emission scanning electron microscope (FEI Strata DB235) operated in secondary electron mode. The distance between sample and objective lens was about $5 \mathrm{~mm}$ during the imaging. The accelerating voltage was $5 \mathrm{kV}$.

The XPS system was a commercial Axis Ultra spectrometer (Kratos Analytical) with a base pressure of 1 $\times 10^{-9}$ Torr. The source was monochromatized Al $K \alpha$ radiation $(1486.6 \mathrm{eV})$ operated at $90 \mathrm{~W}$; the take off angle was $45^{\circ}$. Spot of analysis was an ellipse with the area $\sim 0.8 \mathrm{~mm}^{2}$. Analyzer and transfer lenses operated at fixed analyzer transmission mode. Survey spectra were an average of three scans with $1 \mathrm{eV} / \mathrm{step}$ and were acquired at a pass energy of $80 \mathrm{eV}$. High-resolution spectra were acquired by averaging five scans at $0.2 \mathrm{eV} / \mathrm{step}$ with a pass energy of $20 \mathrm{eV}$.

The ion gun of the sputtering system was adapted for LEIS spectroscopy. In our measurements, a $1 \mathrm{keV} \mathrm{He}^{4}$ ion beam (10 nA beam current; $1 \mathrm{~mm}^{2}$ beam size) was incident at the surface at $45^{\circ}$ with respect to the surface plane. The ions scattered at $135^{\circ}$ were detected by analyzer operating in positive charged particle detection mode. Spectra were taken in the full energy range up to $1 \mathrm{keV}$ with a $0.5 \mathrm{eV} / \mathrm{step}$ and a dwell time of $300 \mathrm{~ms}$. Both XPS and LEIS spectra were fitted using CASAXPS software. ${ }^{29}$

The sample was a polycrystalline $\mathrm{Ru}$ film (31 nm thick) grown on the rectangular cut of the silicon wafer $(18 \times 12$ $\left.\times 0.6 \mathrm{~mm}^{3}\right)$. The sample was mounted on aluminum puck attached to the XPS sample holder. The assembly efficiently dissipates heat load.

Hydrogen exposures were performed in the preparation chamber with the base pressure $\sim 1 \times 10^{-8}$ Torr. Molecular hydrogen $\left(\mathrm{H}_{2}\right.$; Matheson Tri Gas, $\left.99.9999 \%\right)$ was exposed through a leak valve and cracked ${ }^{30}$ directly on the high temperature iridium filament ( $\varnothing 0.008$ in. iridium wire; $99.9 \%$, e-Filaments, LLC) shaped as Fermat's (parabolic) spiral. The filament was placed approximately $4 \mathrm{~cm}$ in front of the sample surface and operated at $2000{ }^{\circ} \mathrm{C}$. The partial pressure of the $\mathrm{H}_{2}$ gas was maintained at the level $5 \times 10^{-4}$ Torr. The filament operated in a sequence of heating/cooling cycles to keep surface temperature below $330 \mathrm{~K}$ and to avoid substantial radiative heat load and the heat associated with hydrogen recombination. The $\cdot \mathrm{H}$ doses $\left(\mathrm{cm}^{-2}\right)$ shown in this article are based on an average flux of $1.8 \times 10^{16} \mathrm{~s}^{-1} \mathrm{~cm}^{-2}$ producing by the source at the sample surface. This flux is calculated using Hertz-Knudsen formula for the $\mathrm{H}_{2}$ molecules impinging upon the filament surface, which cracks $50 \%$ of the molecules. The mean free path of hydrogen atoms between collisions (leading to the recombination) is assumed $4 \mathrm{~cm}$. Our estimation is in general agreement with the experimentally measured $\cdot \mathrm{H}$ flux produced by thermal source. ${ }^{30-32}$

The source of Sn was a lead-free soft soldering wire (Stan Rubinstein Assoc., Inc.) composed of pure Sn. The solder is melted on a $2.5 \mathrm{~mm}$ diameter loop made of thin $\mathrm{Cu}$ wire $(\varnothing 0.2 \mathrm{~mm}$ ). This design produced an effective $\mathrm{Sn}$ surface area $4 \mathrm{~mm}^{2}$ faced toward the sample. The source of Sn was cleaned in ultrasonic washer with acetone followed by cleaning in ethanol and in ultrapure water, then dried with nitrogen flow, and, finally, mounted close to the edge of the sample at tilt angle $45^{\circ}$ and $1 \mathrm{~mm}$ above its surface. The analysis spot was at the opposite side of the sample approximately $12 \mathrm{~mm}$ away from the loop with Sn. During experiments, the source was kept at RT.

\section{RESULTS}

\section{A. Exposure of $\mathrm{Ru}$ film to $\cdot \mathrm{H}$ in the presence of $\mathrm{Sn}$}

Photoelectron spectra recorded for $\mathrm{Ru}$ film exposed to various doses of atomic $\mathrm{H}$ are illustrated by Fig. 1. Tag "Sn+H" in the graph indicates that exposures are done in the presence of Sn. The spectra show evolution of $\mathrm{Sn} 3 d / \mathrm{Ru} 3 p$ energy region. The dash lines represent the results of fitting. Initial spectrum taken before admission of $\mathrm{H}_{2}$ is marked "as installed." It reveals two core level emissions lines $\mathrm{Ru} 3 p_{3 / 2}$ $(461.3 \mathrm{eV})$ and $\mathrm{Ru} 3 p_{1 / 2}(483.6 \mathrm{eV})$ associated with $\mathrm{Ru}$ film.

Subsequent $\mathrm{H}$ exposure results in dramatic change in this region: $\mathrm{H}$ dose $1.6 \times 10^{19} \mathrm{~cm}^{-2}$ leads to the increase in the total $\mathrm{Ru} 3 p$ signal as a result of the removal of an overlayer of air gases (carbon monoxide, dissociated fragments of hydrocarbons, and water) and as a result of reduction in surface oxides by chemically active hydrogen atoms. ${ }^{21,33}$ Figure 2(a) illustrates a rapid drop of $\mathrm{O} 1 s$ peak integral after the same $\mathrm{H}$ dose. It is accompanied by a sudden increase in $\mathrm{Ru} 3 d$ signal. The corresponding spectra are shown in Fig. 3 (O $1 s$ region) and Fig. 4 ( $\mathrm{Ru} 3 d$ region). First $\mathrm{H}$ exposure also leads to formation of a new feature in $\mathrm{Ru} 3 p$ region at around $471 \mathrm{eV}$ (Fig. 1). We attribute this weak bump to inelastic scattering of the photoelectrons. ${ }^{34}$

The spectrum measured after $\mathrm{H}$ dose $1.6 \times 10^{19} \mathrm{~cm}^{-2}$ (Fig. 1) exhibits a new, weak feature at $\sim 493 \mathrm{eV}$. The sub- 


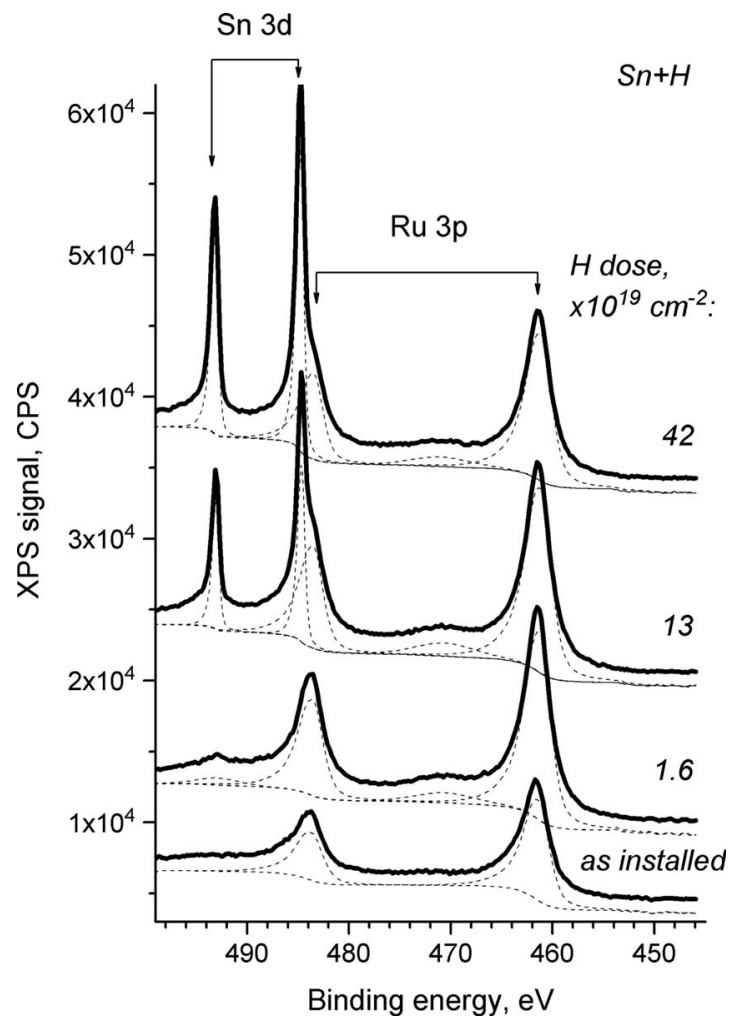

FIG. 1. Photoelectron spectra (mono-Al $K \alpha$ ) measured in $\mathrm{Sn} 3 d / \mathrm{Ru} 3 p$ energy region during sample exposure to the atomic hydrogen in the presence of Sn. The dash lines represent fittings which are shifted vertically for clarity.

sequent $\mathrm{H}$ exposure reveals a strong pair of $\mathrm{Sn}$ lines: $\mathrm{Sn} 3 d_{5 / 2}$ $(484.5 \mathrm{eV})$ and $\mathrm{Sn} 3 d_{3 / 2}(492.9 \mathrm{eV})$. Photoelectron emission from $\mathrm{Sn}$ goes up with $\mathrm{H}$ dose indicating the growth of $\mathrm{Sn}$ overlayer on Ru surface. The dynamics is illustrated by plot in Fig. 2(a). Effective thickness of Sn layer deposited after . $\mathrm{H}$ dose $4.2 \times 10^{20} \mathrm{~cm}^{-2}$ is $\approx 2.5 \AA$ as estimated from ratio of $\mathrm{Sn} 3 d$ to $\mathrm{Ru} 3 d$ signals. Corresponding effective coverage is $\approx 0.85 \mathrm{ML}$ (based on an average interatomic distance of 2.99 $\AA$ in bulk Sn with a density of $7.365 \mathrm{~g} / \mathrm{cm}^{3}$ ).
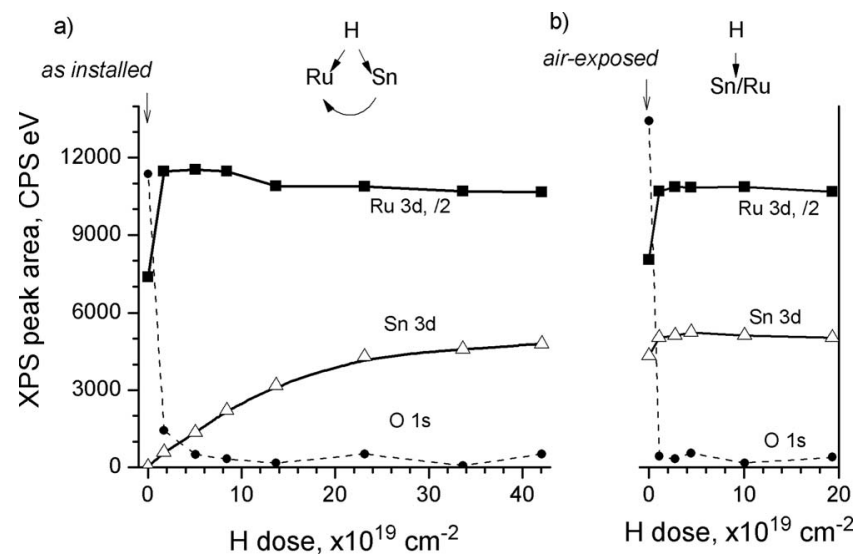

FIG. 2. Variation in the XPS peak areas in O $1 s$ (circles), Sn $3 d$ (triangles), and $\mathrm{Ru} 3 d$ (squares) energy regions during sample exposure to atomic $\mathrm{H}$ in the presence of $\mathrm{Sn}$ (a) and the exposure after surface oxidation and removal of Sn source (b)

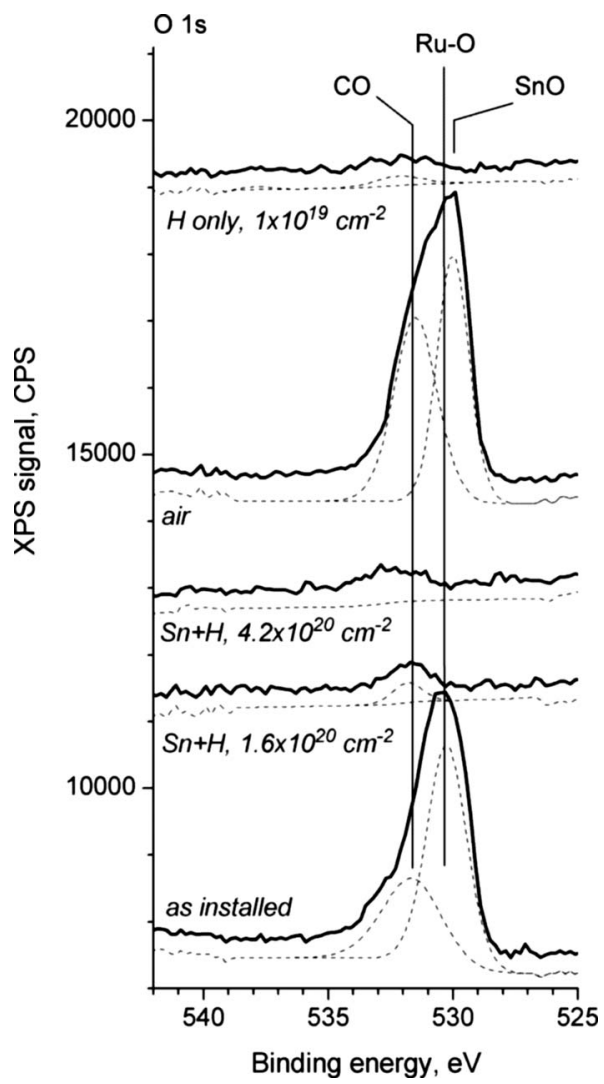

FIG. 3. Photoelectron spectra measured in $\mathrm{O} 1 s$ region at various stages of sample processing: before (as installed) and after sample exposure to the atomic $\mathrm{H}$ in the presence of solder $(\mathrm{Sn}+\mathrm{H})$ followed by air exposure (air) and subsequent $\mathrm{H}$ exposure with $\mathrm{Sn}$ source removed ( $\mathrm{H}$ only). The plot illustrates oxidation, reduction, and reoxidation of the surface.

\section{B. Distribution of Sn across the surface}

We measured the distribution of Sn concentration across $\mathrm{Ru}$ surface after $\cdot \mathrm{H}$ dose $1.3 \times 10^{20} \mathrm{~cm}^{-2}$. The variation in

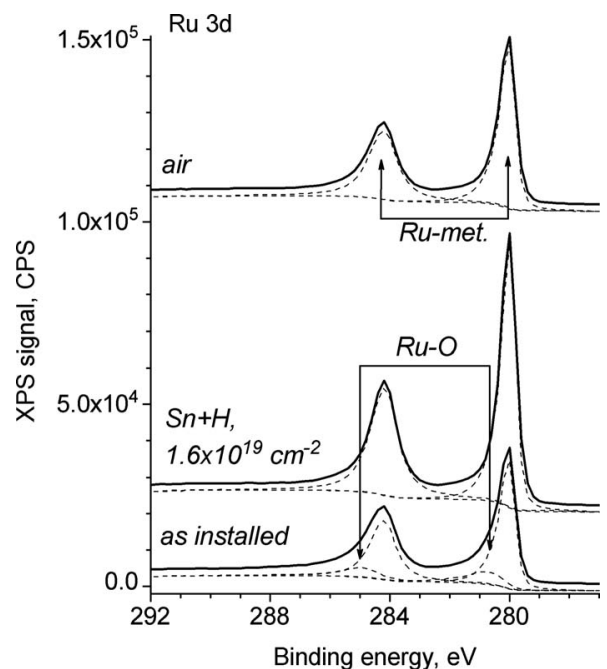

FIG. 4. Photoelectron spectra measured in Ru $3 d / \mathrm{C} 1 s$ energy region for the bare $\mathrm{Ru}$ film before $\mathrm{H}$ exposure (as installed) and then after 1.6 $\times 10^{19} \mathrm{~cm}^{-2} \cdot \mathrm{H}$ in the presence of solder $(\mathrm{Sn}+\mathrm{H})$. The curve air is for oxidized $\mathrm{Sn} / \mathrm{Ru}$ surface (after dose $4.2 \times 10^{20} \mathrm{~cm}^{-2} \cdot \mathrm{H}$ in the presence of $\mathrm{Sn}$ followed by air exposure). 
Sn $3 d$ XPS signal was very subtle as we moved away from the Sn source: the difference of the signals between two spots located $15 \mathrm{~mm}$ apart was $\sim 10 \%$ only. Assuming radial distribution of $\mathrm{Sn}$ emission from a point source, one can expect the surface concentration of Sn to be inversely proportional to $R^{2}$, where $R$ is the distance from the $\mathrm{Sn}$ source. For our experimental geometry, this would mean a 50 times drop of the Sn signal across the surface. In contrast, we observe a very weak dependence of $\mathrm{Sn}$ concentration on $R$. This indicates that a precursor carrying out $\mathrm{Sn}$ to $\mathrm{Ru}$ surface originates from a diffuse source. Therefore, thermal evaporation of $\mathrm{Sn}$ is not responsible for the $\mathrm{Sn}$ transport. Besides, the vapor pressure of $\mathrm{Sn}$ is very low: $\ll 10^{-13}$ Torr (Ref. 35) at RT. We rule out excessive heating of Sn (due to the radical recombination or radiative heating) as our design of the sample/holder/source assembly dissipates heat efficiently. In the text below, we will ascribe Sn transport to the formation of tin hydride followed by its dissociation on the catalytically active $\mathrm{Ru}$ surface.

\section{Effect of $\cdot \mathrm{H}$ on the Sn source}

The effect of atomic $\mathrm{H}$ on Sn source was studied additionally. The XPS spectra measured from Sn source surface were taken before the first hydrogen exposure and after two cumulative doses of hydrogen: $1.6 \times 10^{19}$ and $4.2 \times 10^{20} \mathrm{~cm}^{-2}$ (not shown). Initially, the surface of the source contained mainly $\mathrm{SnO}_{2}$ covered or intermixed with carbonaceous species. The $\cdot \mathrm{H}$ dose $1.6 \times 10^{19} \mathrm{~cm}^{-2}$ led to the reduction in $\mathrm{Sn}$ and a complete removal of carbon. Sn $3 d_{5 / 2}$ peak revealed $2.4 \mathrm{eV}$ chemical shift from 487.3 to $484.9 \mathrm{eV}$ indicating the transition from $\mathrm{Sn}(\mathrm{IV})$ to metallic $\mathrm{Sn}^{36}$ Some residue (sub-at. \%) of $\mathrm{Sn}(\mathrm{II})$ was, however, seen through all $\mathrm{H}$ exposures as evidenced by a small $\mathrm{Sn} 3 d_{5 / 2}$ peak at $486.8 \mathrm{eV}$.

\section{Surface occupation}

The surface occupation of Ru film was characterized with LEIS. ${ }^{37}$ Figure 5 shows sequential spectra detected with increasing $\mathrm{He}^{+}$dose (a) for bare $\mathrm{Ru}$ film exposed to 1.6 $\times 10^{19} \mathrm{~cm}^{-2} \cdot \mathrm{H}$ with no $\mathrm{Sn}$ in the chamber and (b) for Ru film exposed to $4.2 \times 10^{20} \mathrm{~cm}^{-2} \cdot \mathrm{H}$ in the presence of $\mathrm{Sn}$.

The spectra in Fig. 5(a) reveal an increase in the total signal with ion irradiation time. This growth slows down at higher $\mathrm{He}^{+}$doses and saturates after $\sim 40 \mathrm{~min}$ of ion gun operation. Fitting of the spectra (dash lines; asymmetric Gaussian-Lorentzian line shape) requires inclusion of two components at $\sim 840$ and at $\sim 875 \mathrm{eV}$. We attribute both features to scattering of $\mathrm{He}$ by $\mathrm{Ru}$ atoms. The lower energy feature at $\sim 840 \mathrm{eV}$ may result from backscattering of $\mathrm{He}$ in deeper layers accompanied by reionization process. ${ }^{37}$ XPS did not detect any element on the surface (except $\mathrm{Ru}$ ) that may contribute to the signal at these kinetic energies. Very similar low energy tail in the spectrum of $1 \mathrm{keV} \mathrm{He}^{+}$scattered from bare $\mathrm{Ru}$ is also present in two earlier studies: of $\mathrm{Al}$ growth on $\mathrm{Ru}(0001)$ (Ref. 38) and of erosion of $\mathrm{Ru}-$ coated glancing incidence mirrors. ${ }^{39}$
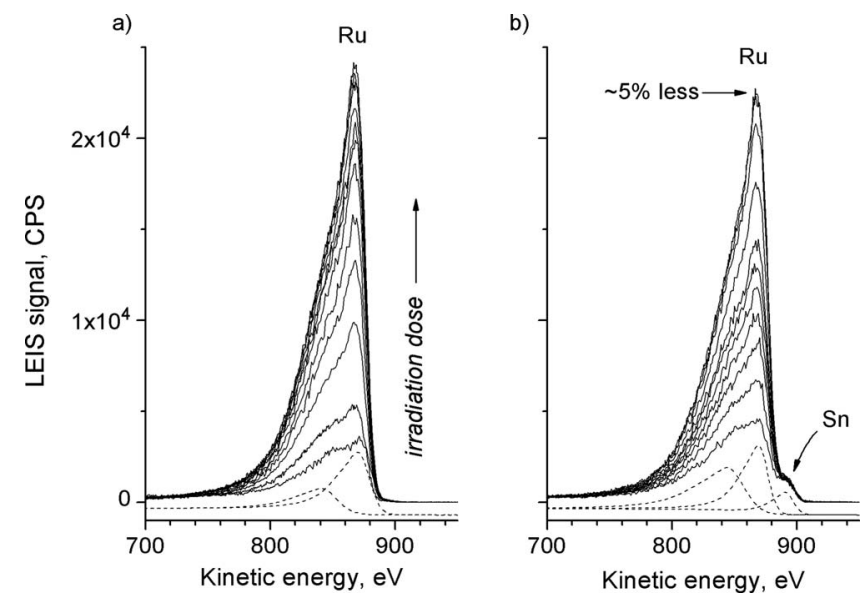

FIG. 5. LEIS spectra $\left(\mathrm{He}^{4}, 1 \mathrm{keV}\right)$ measured for bare $\mathrm{Ru}$ (a) exposed to $1.6 \times 10^{19} \mathrm{~cm}^{-2} \cdot \mathrm{H}$ before $\mathrm{Sn}$ source was introduced into the chamber and (b) after $4.2 \times 10^{20} \mathrm{~cm}^{-2} \cdot \mathrm{H}$ in the presence of $\mathrm{Sn}(\mathrm{b})$. The different curves correspond to various doses of $\mathrm{He}$ ions. The dash lines represent fits. For the same $\mathrm{He}^{+}$doses, the signal from $\mathrm{Ru}$ is about $5 \%$ less from the surface containing $\mathrm{Sn}$ as compared to the clean surface.

Spectra recorded after $\cdot \mathrm{H}$ dose $4.2 \times 10^{20} \mathrm{~cm}^{-2}$ in the presence of Sn [Fig. 5(b)] show the same tendency: the raise of the Ru signal with He dose followed by saturation. In both cases (with and without $\mathrm{Sn}$ ), we assign the increase in $\mathrm{Ru}$ signal to the He-promoted recombination and desorption of hydrogen from Ru surface. The area under Ru components of the saturated spectrum in Fig. 5(b) is $\sim 5 \%$ less than that in Fig. 5(a), indicating that the effective surface area of $\mathrm{Ru}$ is also $5 \%$ less as compared to the $\mathrm{Sn}$-free surface.

The spectra in the Fig. 5(b) reveal an additional peak at $\sim 895 \mathrm{eV}$. The kinetic energy is consistent with scattering of $\mathrm{He}$ by $\mathrm{Sn}$ atoms. In contrast to $\mathrm{Ru}$, the area of $\mathrm{Sn}$ peak does not change with the $\mathrm{He}^{+}$exposure time; it remains virtually unaltered, indicating no change in the total area occupied by Sn on the surface.

We also studied the effect of prolonged $\mathrm{He}^{+}$bombardment on the surface composition. XPS signal in Sn $3 d$ region measured after taking LEIS sequence shown in Fig. 5(b) dropped down to $\sim 70 \%$ of its initial value (i.e., before LEIS), indicating the decrease in the total concentration of Sn due to ion-induced processes (e.g., desorption or bulk diffusion).

\section{E. Surface morphology}

SEM was employed to examine the surface of the sample after $\cdot \mathrm{H}$ dose $4.2 \times 10^{20} \mathrm{~cm}^{-2}$ in the presence of Sn. The sample was taken out of analysis chamber and transported to the SEM facility. The SEM image of small area 1.5 $\times 1.5 \mu \mathrm{m}^{2}$ of air-exposed $\mathrm{Ru}$ film with $\mathrm{Sn}$ overlayer is shown in Fig. 6. It reveals a uniform morphology with rarely distributed particles of unequal sizes up to $\sim 40 \mathrm{~nm}$ in diameter. The particles appear as bright objects with stronger secondary electron emission signal as compared to the other surface areas. These particles (or islands) are homogenous, mostly rounded and formed presumably by Sn. The SEM images of unexposed sample (not shown here) do not reveal these objects. A slightly higher secondary electron yield 


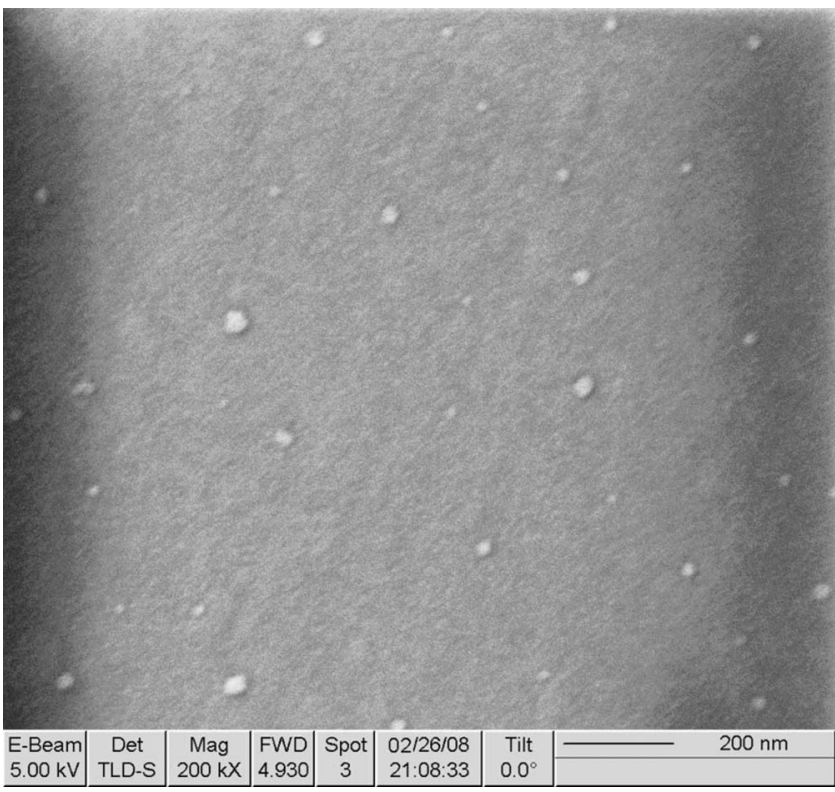

FIG. 6. SEM image (5 keV) measured for Ru-coated sample exposed to atomic hydrogen in the presence of tin. The image area is $1.5 \times 1.5 \mu \mathrm{m}^{2}$. Corresponding effective Sn coverage determined by XPS is $\approx 1 \mathrm{ML}$. The image reveals islands with range of diameters up to $\sim 40 \mathrm{~nm}$ occupying several percent of the surface area. The cluster heights deduced from XPS and SEM data are up to $20 \mathrm{~nm}$. Tin probably nucleates at the crossroads of grain boundaries.

(SEY) from $\mathrm{Sn}$ is expected. Indeed, maximum SEY $\delta_{m}$ from $\mathrm{Ru}$ is $\sim 1.1,{ }^{40}$ and from $\mathrm{Sn}$ it is $1.35 .^{35,40}$ The yield from $\mathrm{SnO}_{2}$ is $3.2{ }^{35}$ In Sec. III F, we will show that our airexposed sample contains $\mathrm{Sn}^{2+}$; $\mathrm{Ru}$ remains in the metallic form. Hence, a brighter SEM image from Sn is anticipated.

\section{F. Air exposure}

We also studied the effect of high pressure oxidation on the $\mathrm{Ru}$ film with $\mathrm{Sn}$ overlayer. Figure 3 shows the evolution of $\mathrm{O} 1 s$ energy region through various processing steps: before and after reduction and after reoxidation of the film. The initial bare Ru surface (marked "as installed") reveals two features. We attribute the peak located at $\sim 531.6 \mathrm{eV}$ to physisorbed species (e.g., carbon monoxide ${ }^{41}$ ), and the peak at $\sim 530.2 \mathrm{eV}$ to chemisorbed oxygen and hydroxyl radicals attached directly to $\mathrm{Ru}^{42}$ The presence of oxidic form of $\mathrm{Ru}$ is also confirmed by $\mathrm{Ru} 3 d$ region (Fig. 4), where appropriate fitting requires inclusion of two spin-splitted pairs: metallic pair with $\mathrm{Ru} 3 d_{5 / 2}$ peak located at $280.0 \mathrm{eV}$ and oxidic one shifted by $0.7 \mathrm{eV}$ toward higher binding energies $\left(\mathrm{Ru} 3 d_{5 / 2}\right.$ at $280.7 \mathrm{eV}) .{ }^{43} \mathrm{Ru} 3 d_{3 / 2}$ photoemission overlaps with $\mathrm{C} 1 s$ lines from adventitious carbon and $\mathrm{CO}$, which are present on the surface of as installed sample. However, C $1 s$ contribution (not shown in Fig. 4) is very weak due to the low concentration of carbon and due to its much lower elemental sensitivity as compared to one of Ru.

Exposure of the surface to atomic $\mathrm{H}$ reduces $\mathrm{Ru}$ : both $\mathrm{Ru}-\mathrm{O}$ component in $\mathrm{Ru} 3 d$ region (Fig. 4; curve " $\mathrm{Sn}+\mathrm{H}$ ") and corresponding O $1 s$ signal (Fig. 3) disappear. Still, some small amount of physisorbed species is detected in $\mathrm{O} 1 \mathrm{~s}$

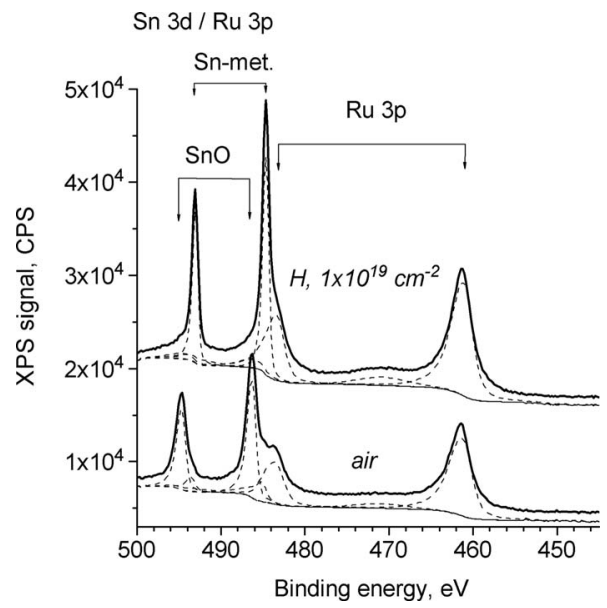

FIG. 7. Photoelectron spectra measured in $\mathrm{Sn} 3 d / \mathrm{Ru} 3 p$ region for $\mathrm{Ru}$ film covered by Sn $(\sim 1 \mathrm{ML})$. The sample was oxidized by exposing it to the air in preparation chamber to mimic high pressure oxidation (curve air). The oxidation was followed by $1 \times 10^{19} \mathrm{~cm}^{-2} \cdot \mathrm{H}$ with no $\mathrm{Sn}$ source $(\mathrm{H}, 1$ $\left.\times 10^{19} \mathrm{~cm}^{-2}\right)$.

region as a result of readsorption of background gases during sample transfer between analysis and preparation chambers.

To mimic high pressure oxidation of the $\mathrm{Sn}$-covered $\mathrm{Ru}$ film, we moved sample to preparation chamber and vented it. Air exposure resulted in reappearance of low energy peak in O $1 s$ region (Fig. 3; curve "air"). Note that this oxide peak was shifted toward lower energy $\sim 529.8 \mathrm{eV}$. The air exposure also led to $1.8 \mathrm{eV}$ shift of $\mathrm{Sn} 3 d$ pair toward higher binding energies (Fig. 7; curve air) resulting in the appearance of Sn $3 d_{5 / 2}$ peak at $486.3 \mathrm{eV}$. These transformations in $\mathrm{O} 1 s$ and $\mathrm{Sn} 3 d$ regions are consistent with formation of $\mathrm{SnO}$ (Refs. 18 and 44) rather than $\mathrm{SnO}_{2}{ }^{18,36}$ For $\mathrm{SnO}_{2}$, it is expected a higher energy shift $(2.2-2.5 \mathrm{eV})$ as well as appearance of $\mathrm{O} 1 s$ oxide feature at binding energies higher than the one we observe in our spectra. The reaction affected nearly every $\mathrm{Sn}$ atom on the surface. Surprisingly, the air exposure of $\mathrm{Ru}$ film with $\mathrm{Sn}$ overlayer did not lead to oxidation of Ru. This is indicated by the absence of $\mathrm{Ru}-\mathrm{O}$ components in $\mathrm{O} 1 s$ (Fig. 3; curve air) and Ru $3 d$ (Fig. 4; curve air) regions. After surface oxidation, the intensity of Ru $3 d$ peak dropped down as seen from comparison of the signals measured from the same sample before [last data point in Fig. 2(a)] and after air exposure [first data point in Fig. 2(b)]. This is in contrast to the bare Ru film, where both Ru $3 d$ and $\mathrm{O} 1 s$ regions (not shown here) indicate that the surface reduced with $\cdot H$ reoxidizes readily when exposed to the air.

\section{G. Stability of Sn on Ru}

We made an effort to remove Sn from Ru surface by flowing atomic $\mathrm{H}$ in the absence of $\mathrm{Sn}$ source. The dynamics of the regional signals is shown in Fig. 2(b) as a function of $\mathrm{H}$ dose. The figure demonstrates dramatic initial effect: an abrupt increase in Sn $3 d$ and drop of O $1 s$ signals due to reduction in the oxidized layer formed as a result of sample exposure to the air gases (to demount $\mathrm{Sn}$ source). Sn was rapidly reduced to metallic form by a relatively low dose of 
$\cdot \mathrm{H}$ as seen from backward chemical shift $-1.8 \mathrm{eV}$ of $\mathrm{Sn} 3 d$ doublet (Fig. 7; compare curves air and "H only, 50 L") and from disappearance of oxidic component in $\mathrm{O} 1 s$ region (Fig. $3)$.

Despite our expectation the prolonged $\cdot \mathrm{H}$ exposure did not lead to a substantial decrease in the Sn concentration on the surface (Fig. 7). After a $\mathrm{H}$ exposure of $1.9 \times 10^{20} \mathrm{~cm}^{-2}$, the surface still contained more than $90 \%$ of the initial Sn concentration. The stability of low coverages of $\mathrm{Sn}$ on $\mathrm{Ru}$ film with respect to $\cdot \mathrm{H}$ was recently noted by Fujima et al. ${ }^{27}$ who reported that blowing hydrogen radicals onto the surface removed Sn almost completely leaving some residual islands of $\mathrm{Sn}$.

\section{DISCUSSION}

\section{A. Morphology of Ru film}

Ruthenium layer used in our experiments was formed on Si substrate by magnetron sputtering technique. The properties of sputter produced films depend strongly on deposition conditions. Sputtered Ru films deposited by incident flux normal to the substrate are usually continuous and typically exhibit a normal texture. ${ }^{45}$ The cross-sectional highresolution transmission electron microscopy images ${ }^{46}$ for 20 $\mathrm{nm} \mathrm{Ru}$ film indicate a smooth layer with a columnar microstructure oriented vertically with respect to the substrate. At low deposition temperatures, Ru films are made of randomly oriented small grains ${ }^{47}$ with typical size ranging from a few to tens of nanometers. ${ }^{48}$ The grain size increases with deposition temperature and the texture with predominant $\langle 0001\rangle$ orientation can be developed. At temperatures $\geq 400{ }^{\circ} \mathrm{C}$, rf magnetron sputtering of $\mathrm{Ru}$ forms on $\mathrm{Si}$ substrate highly $c$-oriented films with smooth surface. We assume that our 31 $\mathrm{nm}$ thick $\mathrm{Ru}$ films are composed of $\{0001\}$ domains with grain boundaries and amorphous patches occupying around $1 \%$ of the surface area.

\section{B. Adsorption of $\cdot \mathrm{H}$ on $\mathrm{Ru}$}

Adsorption of molecular and atomic hydrogen on the (0001) and (1010) planes of $\mathrm{Ru}$ has been studied extensively. ${ }^{49-56} \mathrm{H}_{2}$ adsorbs on both planes dissociatively at all temperatures. ${ }^{49,55,56}$ After dissociation the chemisorbed $\mathrm{H}$ on $\mathrm{Ru}(0001)$ is located exclusively at the fcc site ${ }^{50}$ forming various structures as the coverage increases.

Low temperature $(100 \mathrm{~K})$ adsorption of atomic $\mathrm{H}$ on $\mathrm{Ru}(0001)$ surface was reported ${ }^{52}$ to saturate at coverage 1.42 $\mathrm{H}$ adatoms per primitive surface unit cell. It is greater than a saturation coverage of $1 \mathrm{ML}$ in the case of dissociative chemisorption of $\mathrm{H}_{2}$. The threshold temperature of recombinative thermal desorption of hydrogen from this surface is $\sim 260-265 \mathrm{~K}$ with the desorption peak above RT, $320 \mathrm{~K}$, accompanied by a wide shoulder at $380 \mathrm{~K}$. The results are consistent with both fcc and hep threefold hollow sites to be occupied at surface coverages above $1 \mathrm{ML}$. On the other plane of ruthenium, $\mathrm{Ru}(10 \overline{1} 0),{ }^{51}$ adsorption of atomic $\mathrm{H}$ at $90 \mathrm{~K}$ also differs slightly from molecular hydrogen experiment producing additional thermal desorption peaks at 115

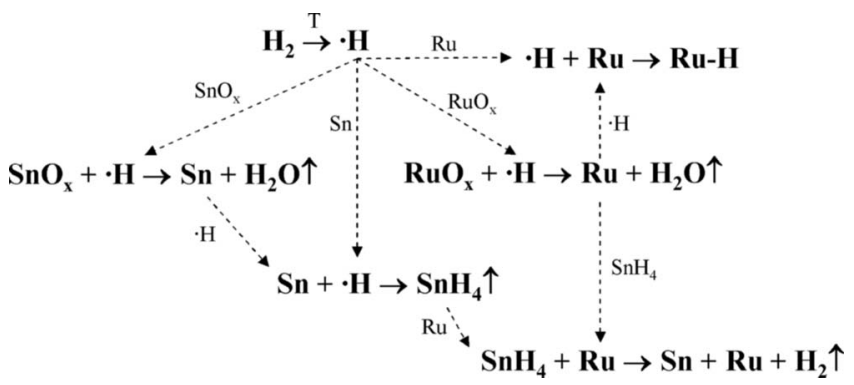

FIG. 8. Scheme of reaction pathways, which agrees with our experimental data. It indicates that atomic $\mathrm{H}$, generated by cracking of $\mathrm{H}_{2}$ on the hot filament, reduces $\mathrm{RuO}_{x}$ and $\mathrm{SnO}_{x}$ oxides, and reacts with $\mathrm{Sn}$ yielding $\mathrm{SnH}_{4}$, which dissociatively adsorbs on Ru surface.

and $150 \mathrm{~K}$. The authors reported that the coverage saturated at $2.5 \mathrm{ML}$. The highest temperature peak $\beta_{3}$ was at $340 \mathrm{~K}$. The reported thermal desorption spectra ${ }^{51}$ indicated that this state contains $\sim 30 \%$ of desorbing molecules.

The solubility of $\mathrm{H}$ in $\mathrm{Ru}$ at RT is very low. ${ }^{57}$ Yates and co-workers ${ }^{58,59}$ reported an evidence for the existence of a binding site for $\mathrm{H}$ below the first atomic layer of $\mathrm{Ru}$ atoms on the $\mathrm{Ru}(0001)$. The existence of subsurface $\mathrm{H}$ on $\mathrm{Ru}(0001)$ was reanalyzed and doubted in later studies. ${ }^{50,60}$

We expect that RT exposure of Ru polycrystalline film to a high flux of atomic $\mathrm{H}$ results in a high coverage of $\mathrm{H}$ adatoms ( $\leq 1 \mathrm{ML}$ ) (reaction $\cdot \mathrm{H}+\mathrm{Ru} \rightarrow \mathrm{Ru}-\mathrm{H}$ in Fig. 8). Neither of the techniques used in the present study can detect hydrogen on the surface. However, the evolution of LEIS measured under low current condition (Fig. 5) implicitly supports the idea that the surface of polycrystalline Ru film at $\mathrm{RT}$ is highly occupied when exposed to atomic $\mathrm{H}$.

\section{Reaction of $\cdot \mathrm{H}$ with $\mathrm{Sn}$}

In our experiments, both $\mathrm{Ru}$ and $\mathrm{Sn}$ are exposed to the mixture of atomic and molecular hydrogen. Sn is very reluctant in reaction with $\mathrm{H}_{2}$; at RT it does not absorb any $\mathrm{H}_{2} .{ }^{61}$ There is an indication of some dissolution of $\mathrm{H}_{2}$ at hydrogen pressures above 10 Torr. $^{62}$ In contrast, atomic $\mathrm{H}$ reacts readily with $\mathrm{Sn}$ to form tin hydride $\mathrm{SnH}_{4},{ }^{63}$ which is volatile at RT (boiling point $221 \mathrm{~K}$ ). Two binary hydrides of $\mathrm{Sn}$ known to date are stannane $\mathrm{SnH}_{4}$ and distannane $\mathrm{Sn}_{2} \mathrm{H}_{6}$; both are characterized by covalent chemical bonding. The chemical ways of production of $\mathrm{SnH}_{4}$ yield a small amount of $\mathrm{Sn}_{2} \mathrm{H}_{6}$ (Refs. 63-65) [can also be formed by vacuum ultraviolet decomposition of $\mathrm{SnH}_{4}$ (Ref. 64)]. At RT, $\mathrm{SnH}_{4}$ slowly decomposes to $\mathrm{Sn}$ and $\mathrm{H}^{65}$ This process is much faster at $370 \mathrm{~K} . \mathrm{Sn}_{2} \mathrm{H}_{6}$ is extremely unstable above $160 \mathrm{~K} ;{ }^{66}$ its halflife at RT is $4 \mathrm{~s} .{ }^{67}$ We believe that under our experimental conditions, atomic $\mathrm{H}$ impinging the surface of $\mathrm{Sn}$ droplet reacts with Sn producing $\mathrm{SnH}_{4}$ (reaction $\mathrm{Sn}+\cdot \mathrm{H} \rightarrow \mathrm{SnH}_{4} \uparrow$ in Fig. 8) and, possibly, some $\mathrm{Sn}_{2} \mathrm{H}_{6}$. The hydride desorbs into a gaseous form and reaches the surface of Ru.

\section{Formation of $\mathrm{Sn}$ islands}

We assume that $\mathrm{SnH}_{4}$, which has a relatively low stability, readily dissociates at RT on the catalytically active surface of 


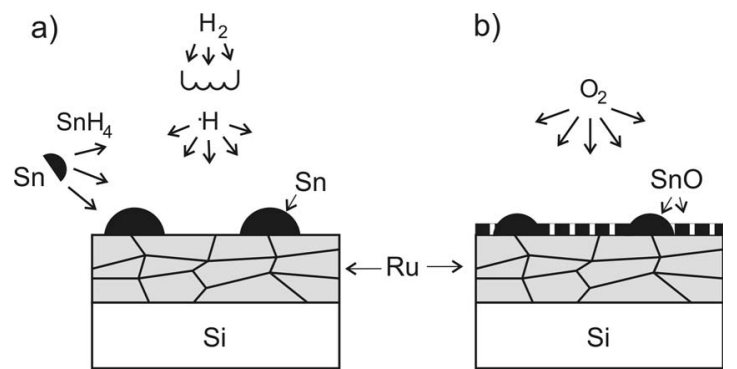

FIG. 9. Sketch illustrating the formation of $\mathrm{Sn}$ clusters on $\mathrm{Ru}$ film via $\mathrm{SnH}_{4}$ dissociation (a) and spreading out of some cluster material after oxidation of Sn (b).

$\mathrm{Ru}$ (reaction $\mathrm{SnH}_{4}+\mathrm{Ru} \rightarrow \mathrm{Sn}+\mathrm{Ru}+\mathrm{H}_{2} \uparrow$ in Fig. 8). It is believed that $d$-band of transition metals plays an important role in dissociative adsorption. ${ }^{68}$ The dissociation may proceed sequentially through several steps as it does in the case of silane $\left(\mathrm{SiH}_{4}\right)$ on $\mathrm{Si}(001)$ surface: ${ }^{69}$

$$
\mathrm{SnH}_{4} \rightarrow \cdot \mathrm{SnH}_{3} \rightarrow \cdot \mathrm{SnH}_{2} \rightarrow \cdot \mathrm{SnH} \rightarrow \mathrm{Sn} .
$$

This Sn transport mechanism illustrated by Fig. 9(a) is in agreement with our observation that a precursor, delivering $\mathrm{Sn}$ to $\mathrm{Ru}$, originates from a diffuse source (Sec. III B). Nucleation of $\mathrm{Sn}$ may proceed via dehydrogenative coupling. ${ }^{70}$ The role of surface defects in dissociation reactions is not clear but activation barrier for such process is probably very low.

Our microscopy data reveal nanometer scale islands of $\mathrm{Sn}$ with wide distribution of lateral dimensions (Fig. 6). The LEIS spectra show low occupation of the Ru surface (Fig. 5) indicating that there is no initial "buffer" layer wetting the surface. In combination these two observations are consistent with Volmer-Weber mechanism ${ }^{71}$ of Sn growth on Ru film at RT. This is in contrast to the result reported for $\mathrm{Ru}(0001)$ at $330 \mathrm{~K}^{17}$ Thermal deposition of Sn led to Stranski-Krastanov growth mode, i.e., island growth over the initial twodimensional (2D) layer. Another recent study ${ }^{72}$ reports the results for vapor deposited Sn on thin Ru film protecting an optical structure. Their LEIS spectra are consistent with fractional surface occupation. We think that the surface of $\mathrm{Ru}$ polycrystalline film has a lower adhesive ability than the surface of a closed packed single crystal leading to the observed difference in $\mathrm{Sn}$ growth mechanisms.

The SEM image in Fig. 6 shows random distribution of $\mathrm{Sn}$ islands on $\mathrm{Ru}$. We speculate that $\mathrm{Sn}$ nucleates at defect sites, presumably at grain boundaries, which usually exhibit a high interfacial energy and a weak bonding. It is not possible to deduce from our data whether $\mathrm{SnH}_{4}$ adsorbs and dissociates on the grains to yield $\mathrm{Sn}$ diffusing to boundaries or it adsorbs at defect sites directly. Under our experimental conditions, Sn deposition is accompanied by adsorption of atomic $\mathrm{H}$. We assume that a large surface area of $\mathrm{Ru}$ is occupied by $\mathrm{H}$, which may hinder $\mathrm{SnH}_{4}$ adsorption, and that the hydride has an easier access to the defect sites. Arena et $a l .{ }^{73}$ reported that the steps on $\mathrm{Ru}(0001)$ surface act as a repulsive barrier for $\mathrm{H}$ diffusion. The activation energy for diffusion along a terrace was measured $13.4 \mathrm{~kJ} / \mathrm{mol}(0.14$
$\mathrm{eV}$ ), and for diffusion over a double atomic step $24.7 \mathrm{~kJ} / \mathrm{mol}$ $(0.26 \mathrm{eV})$. Within experimental error, they found no difference for diffusion up and down the step edges. In the recent theoretical study of dissociative adsorptions of $\mathrm{SiH}_{4}$ and $\mathrm{GeH}_{4}$ on a buckled $\mathrm{SiGe}(100)-2 \times 1$ surface, it was found that $\mathrm{H}$ preadsorption increased energy barrier for hydride adsorption. ${ }^{74}$ Therefore, on $\mathrm{Ru}$ film with $\mathrm{H}$ overlayer, $\mathrm{SnH}_{4}$ may mainly adsorb and dissociate at grain boundaries even if it is kinetically allowed for its fragments, produced on terraces, to diffuse to the selvedge region.

It is implicitly indicated by ion scattering spectra (Fig. 5) that $\cdot \mathrm{H}$ prefers to bind $\mathrm{Ru}$ and does not adsorb on $\mathrm{Sn}$ although one could expect an opposite preference just based on the $\mathrm{Sn}-\mathrm{H}$ bond dissociation energy $(264 \pm 17 \mathrm{~kJ} / \mathrm{mol}$ or $2.74 \mathrm{eV}),{ }^{35,75}$ which exceeds the strength of $\mathrm{Ru}-\mathrm{H}$ bond $(223 \pm 15 \mathrm{~kJ} / \mathrm{mol}$ or $2.31 \mathrm{eV}) .^{35}$ In the earlier study of atomic $\mathrm{H}$ adsorption on the $(\sqrt{3} \times \sqrt{3})-R 30^{\circ} \mathrm{Sn} / \mathrm{Pt}(111),^{76}$ the hydrogen was also asserted to bind only to Pt atoms but not to $\mathrm{Sn}$. In this case the $\mathrm{Pt}-\mathrm{H}$ bond dissociation energy (330 $\mathrm{kJ} / \mathrm{mol}$ or $3.42 \mathrm{eV}$ ) (Ref. 35) is higher than that of $\mathrm{Sn}-\mathrm{H}$ as expected.

\section{E. Oxidation of $\mathrm{Sn} / \mathrm{Ru}$ film and reduction of surface oxides}

The oxidations of neat $\mathrm{Ru}$ film and the film with Sn overlayer exhibit dramatic difference. Polycrystalline $\mathrm{Ru}$ surface oxidizes rapidly when exposed to the air. Natural oxidation affects presumably topmost $\mathrm{Ru}$ atoms and atoms at grain boundaries. Air exposure of Sn clusters on $\mathrm{Ru}$ film results in oxidation of nearly every $\mathrm{Sn}$ atom, but not $\mathrm{Ru}$. The oxidation forms exclusively $\mathrm{SnO}$ with no higher oxides detected. There is a thermodynamic driving force for preferential oxidation of $\mathrm{Sn}$ as the heat of formation per oxygen atom of $\mathrm{Sn}$ oxide [SnO, $280.7 \mathrm{~kJ} / \mathrm{mol}$ (Ref. 35) or $2.91 \mathrm{eV}$ ] is greater than that of $\mathrm{Ru}\left[\mathrm{RuO}_{2}, 305 \mathrm{~kJ} / \mathrm{mol}\right.$ (Ref. 35) or $1.59 \mathrm{eV} / \mathrm{O}$ ]. LEIS data indicate that before oxidation starts, the $\mathrm{Sn}$ atoms are aggregated in 3D islands, which occupy several percent of the surface. According to SEM images (Fig. 6), the air-exposed surface (i.e., the surface after high pressure oxidation) still contains $\mathrm{Sn}$ clusters although the area occupied on $\mathrm{Ru}$ surface is somewhat smaller. Also, XPS shows a drop of Ru signal [Fig. 2(b)] after oxidation. We speculate that the oxidation changes morphology of the film spreading a fraction of Sn islands across the Ru surface, as illustrated by Fig. 9(b). Photoelectrons emitted by $\mathrm{Ru}$ atoms are attenuated by thin Sn overlayer. Similar transformation was reported in earlier study of $\mathrm{Fe}$ adsorption on $\mathrm{TiO}_{2}(110){ }^{77}$ Oxidation of $\mathrm{Fe}$ clusters at $300 \mathrm{~K}$ flattened the overlayer, causing it to spread and completely cover the substrate at $1 \mathrm{ML}$.

The effectiveness of atomic $\mathrm{H}$ in reducing oxides on thin $\mathrm{Ru}$ film $(\sim 2 \mathrm{~nm})$ was studied earlier. ${ }^{21}$ Atomic $\mathrm{H}$ could reduce the amount of oxide formed by irradiation of the surface $\mathrm{Ru}$ with $\sim 100 \mathrm{eV}$ photons in the presence of $\mathrm{H}_{2} \mathrm{O}$. However, the extent of reduction was not clear due to the use of ex situ surface probe techniques, which led to reoxidation of the sample transported through the air. Another study ${ }^{33}$ reports that at $300 \mathrm{~K} \cdot \mathrm{H}$ removes chemisorbed $\mathrm{O}$ from the 
single crystal $\mathrm{Ru}(10 \overline{1} 0)$ nearly completely. However, thermally oxidized $\mathrm{Ru}$ with $\mathrm{RuO}_{2}$ stoichiometry was more resistant to hydrogen, resulting in reduction in the top layer of $\mathrm{RuO}_{2}$ at $300 \mathrm{~K}$, while the bulk remained oxidized. Our photoelectron spectra measured in $\mathrm{O} 1 s$ (Fig. 3) and Ru 3d (Fig. 4) regions show that $\cdot \mathrm{H}$ effectively removes the natural oxides from polycrystalline Ru film. Reaction proceeds via production of water, ${ }^{51}$ which desorbs from the surface at RT (Fig. 8):

$$
\mathrm{RuO}_{2}+4 \mathrm{H} \rightarrow \ldots \rightarrow \mathrm{Ru}+2 \mathrm{H}_{2} \mathrm{O} \uparrow .
$$

Atomic $\mathrm{H}$ was also shown to reduce tin oxide: a thin film of tetragonal $\mathrm{SnO}$ supported on nickel gauze disappeared completely under the action of $\cdot \mathrm{H}^{78}$ In the recent study of influence of atomic $\mathrm{H}$ on transparent conducting oxides, ${ }^{79}$ the authors observed a decrease in the transmittance of $\mathrm{SnO}_{2}$ and detected the appearance of metallic $\mathrm{Sn}$ or $\mathrm{SnO}$ on the surface. In the present work, we observe that $\cdot \mathrm{H}$ is able to reduce both the tin oxide at $\mathrm{Ru}$ surface $[\mathrm{Sn}(\mathrm{II}) \rightarrow \mathrm{Sn}(0)]$ and the bulk oxide $[\mathrm{Sn}(\mathrm{IV}) \rightarrow \mathrm{Sn}(0)]$; some small amount of $\mathrm{Sn}(\mathrm{II})$ inside $\mathrm{Sn}$ source was probably unreachable by $\cdot \mathrm{H}$.

\section{CONCLUSION}

The summary of our findings is illustrated by reaction pathway scheme in Fig. 8. Exposure of $\mathrm{Sn}$ to atomic $\mathrm{H}$ leads to gas-solid reaction, yielding stannane, $\mathrm{SnH}_{4}$. At room temperature the hydride is a volatile gas with reduced stability. It is a precursor of $\mathrm{Sn}$ growth on $\mathrm{Ru}$. $\mathrm{SnH}_{4}$ adsorbs on the surface of polycrystalline Ru film [Fig. 9(a)] dissociatively. The thickest film grown in our study has an effective $\mathrm{Sn}$ coverage $\sim 1$ ML. It consists of randomly distributed 3D islands with an average size up to $\sim 40 \mathrm{~nm}$. Ion scattering data do not reveal the presence of initial 2D wetting layer. Therefore, we infer Volmer-Weber growth mode. ${ }^{71}$ Nucleation of Sn occurs presumably at grain boundaries. This may result from combination of several factors as, for instance, a high interfacial energy at defect sites and a high coverage of $\mathrm{H}$ adatoms on $\mathrm{Ru}$ surface, hindering $\mathrm{SnH}_{4}$ adsorption on terraces.

The high pressure oxidation of $\mathrm{Sn}$ islands on $\mathrm{Ru}$ at room temperature results in morphological transformation of the film spreading Sn across the Ru surface [Fig. 9(b)]. The oxidation forms exclusively $\mathrm{SnO}$ with no higher oxides detected, indicating a low dimensionality of oxidized Sn overlayer. No metallic Sn is found on this surface. The absence of any ruthenium oxide state indicates a strong charge transfer from $\mathrm{Sn}$ to $\mathrm{Ru}$. This is in agreement with assumed morphological transformation of the film. Atomic $\mathrm{H}$ contends effectively against chemisorbed oxygen and natural oxides, which are present on $\mathrm{Ru}$ and $\mathrm{Sn}$. It reduces $\mathrm{RuO}_{2}$ to metallic $\mathrm{Ru}$ on bare $\mathrm{Ru}$ film, and $\mathrm{SnO}$ to metallic $\mathrm{Sn}$ on $\mathrm{Sn} / \mathrm{Ru}$ film.

\section{ACKNOWLEDGMENTS}

The authors are grateful to Professor T. E. Madey (Physics Department, Rutgers University, Piscataway, NJ) and Professor P. C. Zalm (MiPlaza, Philips Research Europe, The
Netherlands) for the helpful discussions, and to Dr. Sergij Yulin (Fraunhofer Institut Angewandte Optik und Feinmechanik, Jena, Germany) for the ruthenium thin film samples prepared for our experiments.

${ }^{1}$ J. G. Chen, C. A. Menning, and M. B. Zellner, Surf. Sci. Rep. 63, 201 (2008).

${ }^{2}$ C. T. Campbell, Annu. Rev. Phys. Chem. 41, 775 (1990).

${ }^{3}$ R. A. Buyanov and N. A. Pakhomov, Kinet. Catal. 42, 64 (2001).

${ }^{4}$ P. Klusoň and L. Červený, Chem. Listy 91, 100 (1997).

${ }^{5}$ T.-S. Tang, K.-Y. Cheah, F. Mizukami, S.-i. Niwa, and M. Toba, J. Am. Oil Chem. Soc. 71, 501 (1994).

${ }^{6}$ S. M. dos Santos, A. M. Silva, E. Jordro, and M. A. Fraga, Catal. Today 107-108, 250 (2005).

${ }^{7}$ A. C. B. Silva, A. P. G. de Sousa, J. D. Ardisson, H. G. L. Siebald, E. Moura, E. N. dos Santos, N. D. S. Mohallem, and R. M. Lago, Mater. Res. 6, 137 (2003).

${ }^{8}$ J. Rodriguez and D. Wayne Goodman, Surf. Sci. Rep. 14, 1 (1991).

${ }^{9}$ T. E. Madey, K. Pelhos, Q. Wu, R. Barnes, I. Ermanoski, W. Chen, J. J. Kolodziej, and J. E. Rowe, Proc. Natl. Acad. Sci. U.S.A. 99, 6503 (2002).

${ }^{10}$ K. Mae and T. Honda, Thin Solid Films 373, 199 (2000).

${ }^{11}$ M. R. Voss, H. Busse, and B. E. Koel, Surf. Sci. 414, 330 (1998).

${ }^{12}$ Y. Li, M. R. Voss, N. Swami, Y.-L. Tsai, and B. E. Koel, Phys. Rev. B 56, 15982 (1997).

${ }^{13}$ T. B. Massalski, J. L. Murray, L. H. Bennett, and H. Baker, Binary Alloy Phase Diagrams (American Society for Metals, Materials Park, OH, 1986).

${ }^{14}$ L. Perring, P. Feschotte, F. Bussy, and J. C. Gachon, J. Alloys Compd. 245, 157 (1996).

${ }^{15}$ J. Charles, L. Perring, J. J. Kuntz, and J. C. Gachon, J. Phase Equilib. 20, 573 (1999).

${ }^{16}$ S. Overbury, P. Bertrand, and G. Somorjai, Chem. Rev. (Washington, D.C.) 75,547 (1975)

${ }^{17}$ M. T. Paffett, A. D. Logan, and T. N. Taylor, J. Phys. Chem. 97, 690 (1993).

${ }^{18}$ A. F. Lee and R. M. Lambert, Phys. Rev. B 58, 4156 (1998).

${ }^{19}$ J. Wang, Y. Wang, S. Xie, M. Qiao, H. Li, and K. Fan, Appl. Catal., A 272, 29 (2004).

${ }^{20}$ P.-Q. Yuan, Y.-M. Ma, Z.-M. Cheng, Y.-A. Zhu, and W.-K. Yuan, THEOCHEM 807, 185 (2007).

${ }^{21}$ H. Oizumi, A. Izumi, K. Motai, I. Nishiyama, and A. Namiki, Jpn. J. Appl. Phys., Part 2 46, L633 (2007).

${ }^{22}$ S. A. Cotton, Chemistry of Precious Metals (Springer, New York, 1997).

${ }^{23}$ R. A. Meyers, Encyclopedia of Physical Science and Technology (Elsevier Science, New York, 2004)

${ }^{24}$ G. W. Schaeffer and S. M. Emelius, J. Am. Chem. Soc. 76, 1203 (1954).

${ }^{25}$ H. O. Funsten, J. W. Boring, R. E. Johnson, and W. L. Brown, J. Appl. Phys. 71, 1475 (1992).

${ }^{26}$ K. Börlin, T. Heinis, and M. Jungen, Chem. Phys. 103, 93 (1986).

${ }^{27}$ K. Fujima, K. Hiraoka, I. Banno, Y. Yuba, and K. Nishihara, presented at the SPIE: Emerging Lithographic Technologies XII, San Jose, CA, 2008 (unpublished), Vol. 6921, p. 6921/6122.

${ }^{28}$ J. P. Allain, M. Nieto, M. Hendricks, A. Hassanein, C. Tarrio, S. Grantham, and V. Bakshi, presented at the Proceedings of SPIE: Emerging Lithographic Technologies XI, San Jose, CA, 2007, Vol. 6517, p. $65171 \mathrm{~V} / 65110$.

${ }^{29}$ N. Fairley, CasaXPS 2.3.14 (Casa Software, Ltd.).

${ }^{30}$ J. John T. Yates, Experimental Innovations in Surface Science: A Guide to Practical Laboratory Methods and Instruments (Springer, New York, 1998).

${ }^{31}$ J. D. Wnuk, J. M. Gorham, B. A. Smith, M. Shin, and D. H. Fairbrother, J. Vac. Sci. Technol. A 25, 621 (2007).

${ }^{32}$ V. Kagadei, E. Nefyodtsev, D. Proskurovsky, and S. Romanenko, Tech. Phys. Lett. 29, 897 (2003).

${ }^{33}$ R. Wasielewski, B. V. Yakshinskiy, M. N. Hedhili, A. Ciszewski, and T. E. Madey, presented at the Proceedings of SPIE: 23rd European Mask and Lithography Conference, Grenoble, France, 2007, Vol. 6533, p. 653316.

${ }^{34}$ A. Salomonsson et al., J. Nanopart. Res. 8, 899 (2006).

${ }^{35}$ D. R. Lide, CRC Handbook of Chemistry and Physics, 88th ed. (CRC, Boca Raton, FL, 2007). 
${ }^{36}$ M. A. Stranick and A. Moskwa, Surf. Sci. Spectra 2, 50 (1993).

${ }^{37}$ H. H. Brongersma, M. Draxler, M. de Ridder, and P. Bauer, Surf. Sci. Rep. 62, 63 (2007).

${ }^{38}$ Y. Wu, H.-S. Tao, E. Garfunkel, T. E. Madey, and N. D. Shinn, Surf. Sci. 336, 123 (1995).

${ }^{39}$ J. P. Allain, A. Hassanein, M. Nieto, V. Titov, P. Plotkin, E. Hinson, B. J. Rice, R. Bristol, D. Rokusek, W. Lytle, B. J. Heuser, M. M. C. Allain, H. $\mathrm{Ju}$, and $\mathrm{C}$. Chrobak, presented at the Proceedings of SPIE: Emerging Lithographic Technologies IX, San Jose, CA, 2005, Vol. 5751, pp. 11101117.

${ }^{40}$ H. Seiler, J. Appl. Phys. 54, R1 (1983).

${ }^{41}$ G. Rotaris, A. Baraldi, G. Comelli, M. Kiskinova, and R. Rosei, Surf. Sci. 359, 1 (1996).

${ }^{42}$ N. S. Faradzhev, K. L. Kostov, P. Feulner, T. E. Madey, and D. Menzel, Chem. Phys. Lett. 415, 165 (2005).

${ }^{43}$ Y. Kaga, Y. Abe, H. Yanagisawa, M. Kawamura, and K. Sasaki, Surf. Sci. Spectra 6, 68 (1999).

${ }^{44}$ M. A. Stranick and A. Moskwa, Surf. Sci. Spectra 2, 45 (1993).

${ }^{45}$ P. Morrow, F. Tang, T. Karabacak, P.-I. Wang, D.-X. Ye, G.-C. Wang, and T.-M. Lu, J. Vac. Sci. Technol. A 24, 235 (2006).

${ }^{46}$ R. Chan, T. N. Arunagiri, Y. Zhang, O. Chyan, R. M. Wallace, M. J. Kim, and T. Q. Hurdc, Electrochem. Solid-State Lett. 7, G154 (2004).

${ }^{47}$ H.-Y. Lee, Y.-W. Hsieh, C.-H. Hsu, and K. S. Liang, Mater. Chem. Phys. 82, 984 (2003).

${ }^{48}$ R. Messier, A. P. Giri, and R. A. Roy, J. Vac. Sci. Technol. A 2, 500 (1984).

${ }^{49}$ M. Tatarkhanov, F. Rose, E. Fomin, D. F. Ogletree, and M. Salmeron, Surf. Sci. 602, 487 (2008).

${ }^{50}$ K. L. Kostov, W. Widdra, and D. Menzel, Surf. Sci. 560, 130 (2004).

${ }^{51}$ E. Vesselli, G. Comelli, and R. Rosei, J. Chem. Phys. 120, 8216 (2004).

${ }^{52}$ T. A. Jachimowski, B. Meng, D. F. Johnson, and W. H. Weinberg, J. Vac. Sci. Technol. A 13, 1564 (1995).

${ }^{53}$ H. Busse, M. R. Voss, D. Jerdev, B. E. Koel, and M. T. Paffett, Surf. Sci. 490, 133 (2001).

${ }^{54}$ M. J. Weiss, C. J. Hagedorn, and W. H. Weinberg, Surf. Sci. 429, 54 (1999).

${ }^{55}$ R. Döll et al., J. Chem. Phys. 108, 8671 (1998).
${ }^{56}$ M. A. Barteau, J. Q. Broughton, and D. Menzel, Surf. Sci. 133, 443 (1983).

${ }^{57}$ R. B. McLellan and W. A. Oates, Acta Metall. 21, 181 (1973).

${ }^{58}$ J. T. Yates, Jr., C. H. F. Peden, J. E. Houston, and D. W. Goodman, Surf. Sci. 160, 37 (1985).

${ }^{59}$ C. H. F. Peden, D. W. Goodman, J. E. Houston, and J. T. Yates, Jr., Surf. Sci. 194, 92 (1988).

${ }^{60}$ P. Feulner, H. Pfnьr, P. Hofmann, and D. Menzel, Surf. Sci. 173, L576 (1986).

${ }^{61}$ A. Sieverts, Zeit. Elektochem. 16, 707 (1910).

${ }^{62}$ E. Baur and R. Brunner, Helv. Chim. Acta 17, 958 (1934).

${ }^{63}$ T. G. Pearson, P. L. Robinson, and E. M. Stoddart, Proc. R. Soc. London, Ser. A 142, 275 (1933).

${ }^{64}$ D. J. Aaserud and F. W. Lampe, J. Phys. Chem. 100, 10215 (1996).

${ }^{65}$ N. N. Greenwood and A. Earnshaw, Chemistry of the Elements, 2 nd ed. (Butterworth-Heinemann, Oxford, 1997).

${ }^{66}$ W. L. Jolly, J. Am. Chem. Soc. 83, 335 (1961).

${ }^{67}$ D. J. Aaserud and F. W. Lampe, J. Phys. Chem. A 101, 4114 (1997).

${ }^{68}$ R. I. Masel, Principles of Adsorption and Reaction on Solid Surfaces (Wiley, New York/IEEE, New York, 1996).

${ }^{69}$ T. Singh, M. S. Valipa, T. J. Mountziaris, and D. Maroudas, J. Chem. Phys. 127, 194703 (2007).

${ }^{70}$ A. G. Davies, Organotin Chemistry (VCH, Weinheim, 1997).

${ }^{71}$ M. Volmer and A. Weber, Z. Phys. Chem. 119, 277 (1926).

${ }^{72}$ J. P. Allain, M. Nieto, M. Hendricks, S. S. Harilal, and A. Hassanein, presented at the Proceedings of SPIE: Damage to VUV, EUV, and X-ray Optics, Prague, Czech Republic, 2007, Vol. 6586, p. 3.

${ }^{73}$ M. V. Arena, E. D. Westre, D. E. Brown, J. Kutzner, and S. M. George, Surf. Sci. 325, 151 (1995).

${ }^{74}$ C.-L. Cheng, D.-S. Tsai, and J.-C. Jiang, Surf. Sci. 600, 3194 (2006).

${ }^{75}$ L. May and C. R. Dillard, J. Chem. Phys. 34, 694 (1961).

${ }^{76}$ E. Janin, M. Bjorkqvist, T. M. Grehk, M. Gothelid, C. M. Pradier, U. O. Karlsson, and A. Rosengren, Appl. Surf. Sci. 99, 371 (1996).

${ }^{77}$ J.-M. Pan and T. E. Madey, J. Vac. Sci. Technol. A 11, 1667 (1993).

${ }^{78}$ M. Piggott, Acta Crystallogr. 10, 364 (1957).

${ }^{79}$ A. Masuda, K. Imamori, and H. Matsumura, Thin Solid Films 411, 166 (2002). 